\title{
Gestational hyperglycemia on diet and medication: impact on placental pathology and pregnancy outcomes
}

\author{
Lalitha Natarajan ${ }^{1}$, G. UmaMaheswari ${ }^{2 *}$
}

${ }^{1}$ Department of Obstetrics and Gynaecology, ${ }^{2}$ Department of Pathology, PSG Institute of Medical Sciences and Research, Coimbatore, Tamil Nadu, India

Received: 12 June 2019

Revised: 27 June 2019

Accepted: 09 July 2019

\section{*Correspondence:}

Dr. G. UmaMaheswari,

E-mail: umsi2giri@gmail.com

Copyright: (c) the author(s), publisher and licensee Medip Academy. This is an open-access article distributed under the terms of the Creative Commons Attribution Non-Commercial License, which permits unrestricted non-commercial use, distribution, and reproduction in any medium, provided the original work is properly cited.

\section{ABSTRACT}

Background: To evaluate the placental morphology and perinatal outcome in patients with gestational hyperglycemia on diet and medication.

Methods: Placental examinations performed at the Department of Pathology between August 2016 to August 2018 were retrospectively reviewed. Of the received 140 placentas, 35 of gestational diabetes (GDM) and pre gestational diabetes were identified and segregated into hyperglycemia on diet and on medication. The clinical details, placental findings and perinatal outcome of patients in both the groups (gestational hyperglycemia on diet and medication) were collected and analyzed.

Results: Among the 35 cases, there were 24 cases of mild gestational hyperglycemia controlled with diet and 11 cases of hyperglycemia on medication (oral hypoglycemic drugs \pm insulin).

Most of the placentae in both the groups weighed less than tenth centile. The cord abnormalities such as hyper coiling, velamentous /marginal insertion and furcate cord were observed more in women with GDM on diet. There was no significant gross placental lesion in those on medication. Placental histological features most consistently associated with both the groups include, disturbances of villous maturation (DVM), Derangements in uteroplacental / foetoplacental circulation and villous capillary lesions. Small for gestational age and intrauterine foetal death were found in both the groups, but more commonly in patients with hyperglycemia on medication.

Conclusions: Villous maturation defects, uteroplacental / foetoplacental malperfusion are the essential placental changes which can result in adverse perinatal outcomes in women with hyperglycemia irrespective of the diabetic control.

Keywords: Gestational diabetes, Gestational hyperglycemia, Perinatal outcome, Placental malperfusion, Placental pathology

\section{INTRODUCTION}

India has the second largest diabetic population in the world after China,with $8.7 \%$ of the total population in the age group 20-70 years being diabetic. ${ }^{1}$ A cross sectional study among 15 states showed an estimated prevalence of
$7.3 \% .^{2}$ Diabetes in pregnancy is a growing health concern among the antenatal mothers in India. A recent metaanalysis shows the pooled estimate for mean prevalence of gestational diabetes to be $10.1 \%$ with a rising trend from $0.53 \%$ to $27.3 \%$. $^{3-5}$ 
Gestational diabetes is defined as glucose intolerance with onset or first recognition during pregnancy and is associated with a multitude of maternal and foetal complications. $^{6}$ There is a higher incidence of spontaneous miscarriages, congenital malformations, macrosomia, intrauterine death, operative deliveries, birth injuries, neonatal respiratory distress, neonatal hypoglycaemia in diabetic pregnancies and increased incidence of type 2 diabetes in offspring. Maternal complications include a higher incidence of preeclampsia, polyhydramnios, obstructed labour, caesarean sections, postpartum haemorrhage and infections.

Placenta is the organ which serves as a means of communication at the maternal foetal interface, meanwhile acting as a selective barrier between both the circulations. Changes in the glycemic status are known to affect the placenta and the resulting histopathological findings are categorised based on the time of onset of hyperglycemia. ${ }^{7,8}$ Earlier onset of altered glycemic profile results in structural alterations whereas later onset causes functional impairment. Common changes observed include villous immaturity, villous fibrinoid necrosis, chorangiosis, and increased angiogenesis.

Hence the placenta may be regarded as a route map guiding us in our understanding of the pathological basis of the foetal complications encountered in diabetic pregnancies.

We sought to determine the placental morphological changes in diabetic pregnancies and to correlate them with neonatal outcome.

\section{METHODS}

In this retrospective study, 35 singleton placentas from mothers with altered/abnormal glucose profile were studied. Institutional ethical committee approval was obtained. The study materials were archived from the departments of Pathology, Obstetrics and gynaecology and from medical record department. The study period was between August 2016 to August 2018 (2 years).

\section{Inclusion criteria}

- Placentas from patients with the clinical history of gestational diabetes / hyperglycemia on diet and medication irrespective of associated comorbidities

\section{Exclusion criteria}

- Unfixed/poorly fixed placental specimen and Placentas with no clinical details will be excluded

Clinical data collected were patient's age, gestational age, obstetric score, co-morbidities and types of glucose intolerance. All the antenatal women were routinely screened for gestational diabetes during 24 to 28 weeks of gestation by the DIPSI OGCT (75 grams glucose load in non-fasting state followed by a 2-hour plasma glucose). ${ }^{9}$ Women with 2 hour plasma glucose more than $140 \mathrm{mg} / \mathrm{dl}$ were categorized as gestational diabetes. They were categorized into 2 groups: Mild gestational hyperglycemia (on diet), diabetes on medication (pregestational /gestational).

Perinatal factors observed were mode of delivery, pregnancy outcome [intrauterine foetal death (IUD), neonatal death], birth weight, Apgar scores and NICU (neonatal intensive care unit) admission. According to the birth weight, the babies are classified as small for gestational age/ foetal growth restriction (SGA/FGR), appropriate for gestational age (AGA) and large for gestational age (LGA).

The placental tissues were fixed in $10 \%$ buffered formalin. The gross parameters observed were trimmed disc weight, measurements, cord (color, length, diameter, number of vessels, twists, insertion site, true/false knots), membranes (color, insertion and rupture site), foetal surface, maternal surface and parenchyma (color, sponginess, location \& size of any lesion, calcification, etc.). ${ }^{10}$

After taking photographs of the foetal and maternal surfaces, 2 bits were taken each from the membrane roll and umbilical cord. The placental parenchyma was then cut into thin slices with the interval of $1.0 \mathrm{~cm}$ (bread loaf method). Picture of the parenchyma was taken for all the placentas. 3 bits were taken from the normal looking central parenchyma and few more from the lesional area (if present grossly). Haematoxylin and eosin stained slides were reviewed, and significant changes were noted.

Since it was a descriptive study with limited numbers, statistical analysis for comparison was not attempted.

\section{RESULTS}

The 35 cases were identified with hyperglycemia in pregnancy. There were 24 cases of mild gestational hyperglycemia controlled with diet and 11 cases of hyperglycemia on medication, which included gestational and pre gestational diabetes.

\section{Mild gestational hyperglycemia on diet $(n=24)$}

\section{Clinical characteristics}

The age distribution of the patients whose placentae were examined ranged from 23 to 40 years with the mean age of 30.83 years. The earliest gestational age was 25 weeks and the maximum was 40 weeks. Fourteen patients were primigravida and ten were multigravida. Half of the placentas were from preterm pregnancies and half from term pregnancies. Associated maternal conditions were analysed with few cases showing comorbidities such as oligohydramnios $(n=3)$,hypertension /preeclampsia $(n=2)$, 
antiphospholipid antibody $(\mathrm{n}=2)$, anemia $(\mathrm{n}=2)$, abruption $(n=2)$ and one each of familial hypercholesterolemia, placenta previa, polyhydramnios and hypothyroidism.

\section{Foetal outcome}

The birth weights of nine $(37.5 \%)$ of the neonates were appropriate for gestational age (AGA). Among the remaining, $8(33 \%)$ were small for gestational age (SGA), $3(12.5 \%)$ were large for gestational age (LGA) and 4 $(16.6 \%)$ of the pregnancies resulted in intrauterine foetal demise (IUFD). Table 1 highlights the perinatal outcome in both the groups.

\section{Placental findings}

Weight: Of the 24 studied placentas, 11 weighed less than the $10^{\text {th }}$ centile $(11 / 24)$. This is in correlation with the growth restriction in 6 foetuses (6/11) and IUD in 1 case (1/11). The remaining small placentas (4/11) were of foetuses with normal weights.

The weights of nine of the placentas $(9 / 24)$ were in the normal range

\section{Gestational and pre gestational diabetes on medication $(n=11)$}

\section{Clinical characteristics}

The age distribution of the patients whose placentae were examined ranged from 25 to 42 years with the mean age of 32.9 years.

The earliest gestational age was 30 weeks and the maximum was 39 weeks. Four patients were primigravida and seven were multigravida. Three of the placentas were from term pregnancies and eight from preterm pregnancies. Associated maternal conditions included were three cases each of gestational hypertension/preeclampsia and hypothyroidism and one each of anemia and immune thrombocytopenic purpura.

\section{Foetal outcome}

Five $(45 \%)$ of the neonates were SGA, 2(18\%) were AGA and $1(9 \%)$ was LGA. The remaining $3(27 \%)$ were IUFD (Table 1).

\section{Table 1: Perinatal outcome in Maternal} hyperglycemia.

\begin{tabular}{|lllll|}
\hline $\begin{array}{l}\text { Number of } \\
\text { patients }\end{array}$ & SGA & LGA & AGA & IUD \\
\hline $\begin{array}{l}\text { GDM on diet } \\
(\mathrm{n}=24)\end{array}$ & 8 & 3 & 9 & 4 \\
\hline $\begin{array}{l}\text { GDM on } \\
\text { medication }(\mathrm{n}=11)\end{array}$ & 5 & 1 & 2 & 3 \\
\hline
\end{tabular}

\section{Placental findings}

Weight: $7 / 11$ placentas weighed less than $10^{\text {th }}$ centile. Four of them were associated with small foetuses and 2 each were associated with AGA and IUD respectively.

\section{Gross features}

Table 2 highlights the gross placental findings including umbilical cord.

\section{Microscopic findings}

Table 3 displays the microscopic features of placenta in both the groups.

Apart from the tabulated findings, calcification, perivillous fibrin deposition, increased NRBCs, subchorionic cysts and mild focal villitis were also observed.

Table 2: Gross placental findings in GDM pregnancies.

\begin{tabular}{|c|c|c|c|c|c|c|c|c|}
\hline \multirow[b]{2}{*}{ Gross placental findings } & \multicolumn{4}{|c|}{ GDM on diet $(\mathrm{N}=\mathbf{2 4})$} & \multicolumn{4}{|c|}{ GDM on medication ( $\mathrm{N}=11)$} \\
\hline & $\begin{array}{l}\text { SGA } \\
(\mathbf{N}=8)\end{array}$ & $\begin{array}{l}\text { AGA } \\
(\mathbf{N}=9)\end{array}$ & $\begin{array}{l}\text { LGA } \\
(\mathbf{N}=3)\end{array}$ & $\begin{array}{l}\text { IUD } \\
(\mathbf{N}=4)\end{array}$ & $\begin{array}{l}\text { SGA } \\
(\mathbf{N}=5)\end{array}$ & $\begin{array}{l}\mathbf{A G A} \\
(\mathbf{N}=2)\end{array}$ & $\begin{array}{l}\text { LGA } \\
(\mathbf{N}=\mathbf{1})\end{array}$ & $\begin{array}{l}\text { IUD } \\
(\mathbf{N}=\mathbf{3})\end{array}$ \\
\hline Succenturiate lobe & 1 & - & - & 1 & - & - & - & - \\
\hline Meconium staining & - & 1 & - & - & - & - & - & 1 \\
\hline Subchorionic hemorrhage & - & - & - & - & - & - & - & 1 \\
\hline Retroplacental hematoma & - & 2 & - & - & - & - & - & - \\
\hline Marginal atrophy & 1 & 3 & - & 1 & - & 1 & 1 & 2 \\
\hline Cord: 1) Hypercoiled & 2 & 1 & 3 & - & 1 & - & - & - \\
\hline 2) Hypocoiled & 1 & - & - & 1 & - & 1 & - & - \\
\hline 3) Velamentous insertion & 1 & - & - & 1 & - & - & - & - \\
\hline 4) Marginal insertion & 2 & - & - & - & - & - & - & - \\
\hline 5) Furcate cord & 1 & - & - & 1 & - & - & - & -- \\
\hline 6) True knot & - & - & 1 & - & - & - & - & - \\
\hline
\end{tabular}


Table 3: Placental microscopic findings in GDM pregnancies.

\begin{tabular}{|c|c|c|c|c|c|c|c|c|}
\hline \multirow[b]{2}{*}{ Placental microscopic findings } & \multicolumn{4}{|c|}{ GDM on diet $(\mathrm{N}=24)$} & \multicolumn{4}{|c|}{ GDM on medication ( $N=11)$} \\
\hline & $\begin{array}{l}\text { SGA } \\
(\mathbf{N}=8)\end{array}$ & $\begin{array}{l}\text { AGA } \\
(\mathrm{N}=9)\end{array}$ & $\begin{array}{l}\text { LGA } \\
(\mathbf{N}=3)\end{array}$ & $\begin{array}{l}\text { IUD } \\
(\mathbf{N}=4)\end{array}$ & $\begin{array}{l}\text { SGA } \\
(\mathrm{N}=5)\end{array}$ & $\begin{array}{l}\text { AGA } \\
(\mathrm{N}=2)\end{array}$ & $\begin{array}{l}\text { LGA } \\
(\mathbf{N}=1)\end{array}$ & $\begin{array}{l}\text { IUD } \\
(\mathbf{N}=\mathbf{3})\end{array}$ \\
\hline DVI (Fig .1) & 5 & 4 & 2 & 2 & 4 & 2 & 0 & 1 \\
\hline Vascular ectasia & 2 & 2 & 2 & 1 & 3 & 0 & 0 & 0 \\
\hline $\begin{array}{l}\text { Villous capillary lesions } \\
\text { (chorangiosis) }\end{array}$ & 3 & 5 & 2 & 1 & 4 & 1 & 1 & 2 \\
\hline Chorangioma & 0 & 1 & 1 & 0 & 0 & 0 & 0 & 0 \\
\hline MVM (infarcts+IVT) & 4 & 6 & 0 & 0 & 5 & 0 & 0 & 2 \\
\hline FVM (Fig .2) & 3 & 2 & 0 & 1 & 3 & 0 & 0 & 1 \\
\hline Laminar necrosis & 2 & 4 & 1 & 1 & 0 & 0 & 1 & 0 \\
\hline A/C CAM (Fig.3) & 1 & 1 & 1 & 1 & 0 & 1 & 0 & 0 \\
\hline Increased syncytial knotting & 2 & 6 & 0 & 0 & 3 & 1 & 1 & 3 \\
\hline Increased cell islands & 3 & 4 & 1 & 1 & 2 & 2 & 1 & 2 \\
\hline CHIV & 0 & 0 & 0 & 1 & 0 & 0 & 0 & 0 \\
\hline
\end{tabular}

DVI, Distal villous immaturity; MVM,maternal vascular malperfusion; IVT, intervillousthrombus; FVM, foetal vascular malperfusion; A/C CAM, acutechorioamnionitis; CHIV, chronic histiocytic intervillositis

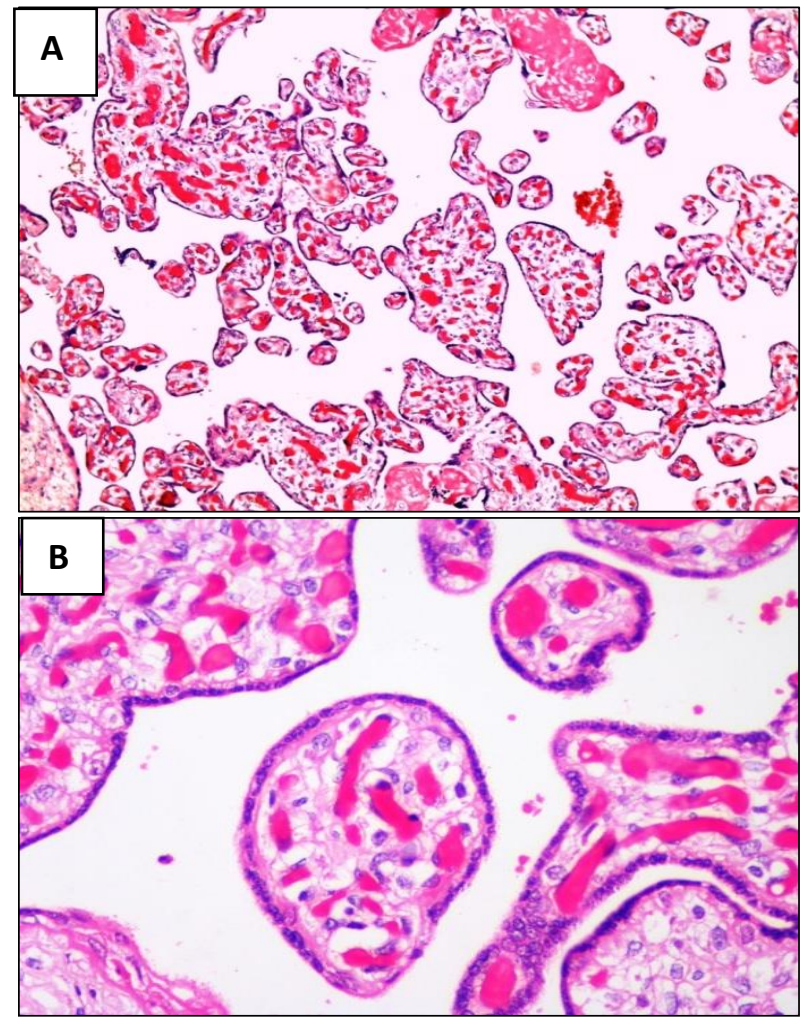

Figure 1: Distal villous immaturity; A) Distal villi are large with irregular outlines. H\&E, 10X; B) They have continuous, thick trophoblastic layer with paucity of vasculosyncytial membranes. H\&E, 40X.

\section{DISCUSSION}

In the present study, we analyzed the placental morphology and clinical outcome in pregnant women with mild hyperglycemia on diet and Gestational and pregestational diabetes on medication.

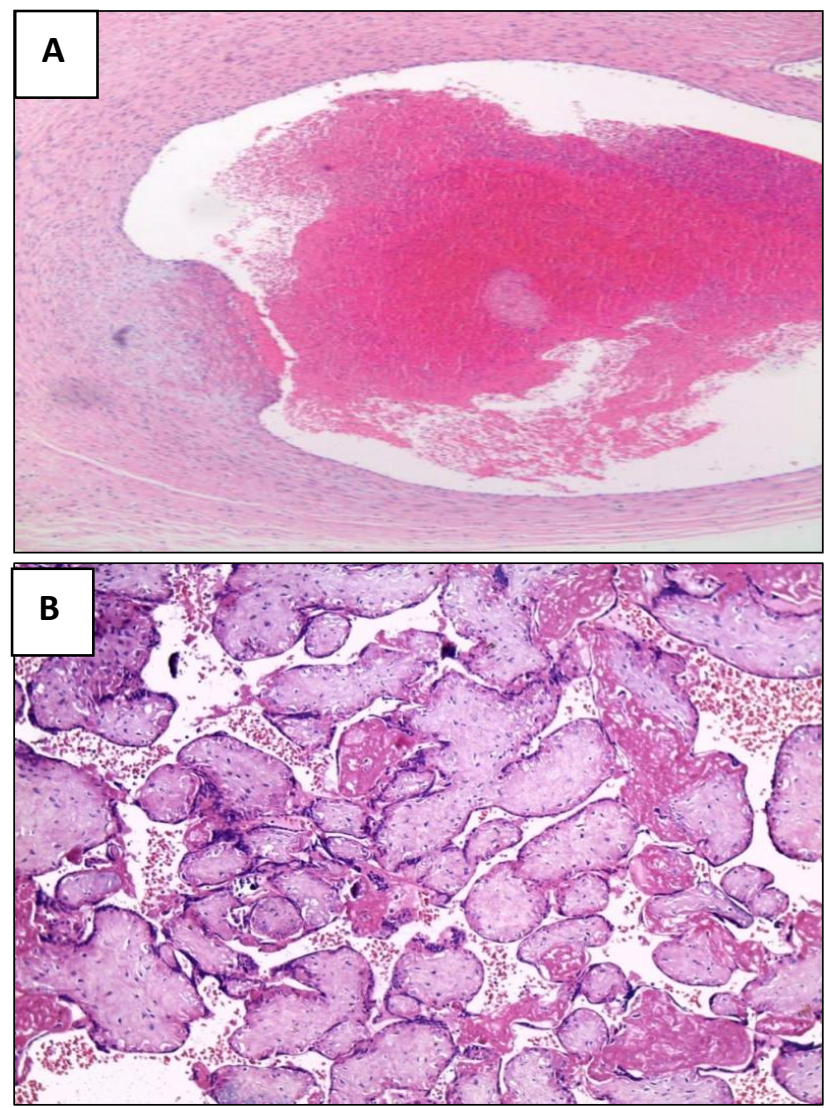

Figure 2: Foetal vascular malperfusion; A). Thrombosis in a chorionic plate vessel; B) Large groups of avascular hyalinized villi. H\&E, 10X. 


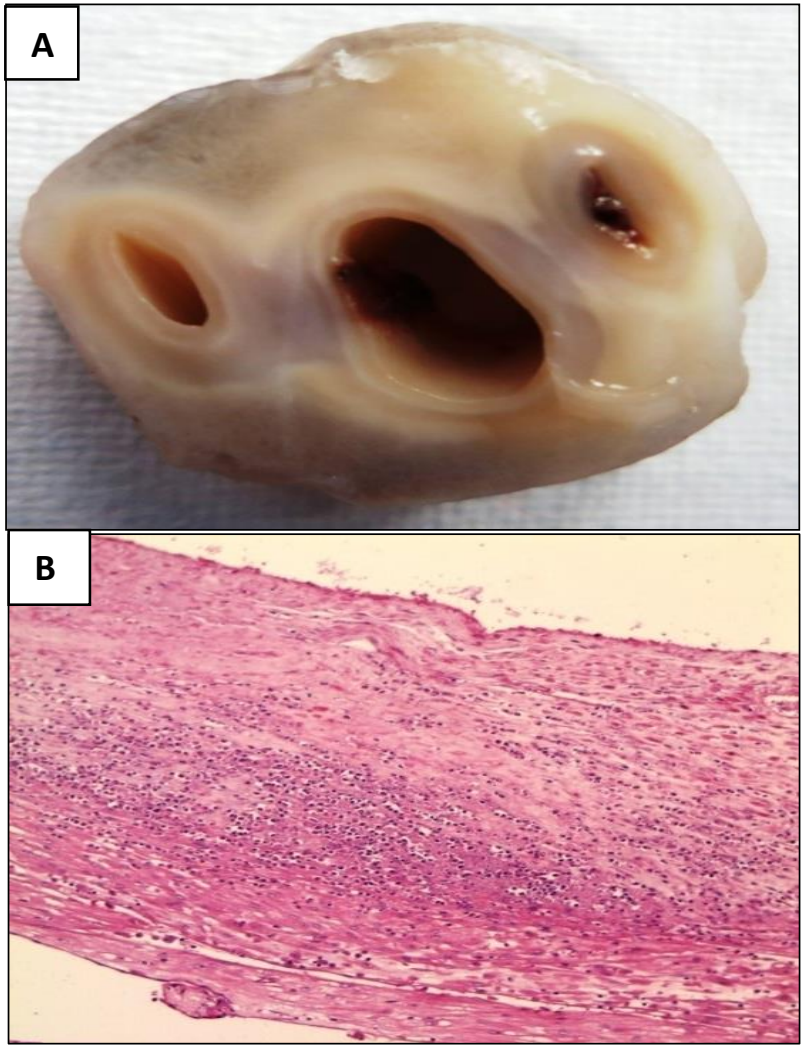

Figure 3: Acute chorioamnionitis; A) Gross image of this cross section of umbilical cord shows thick yellow white rim around the vessels - Necrotizing funisitis; B)

Necrotizing chorioamnionitis -membrane roll. H\&E, 10X.

There have been studies on placentas of diabetic women which have reported large babies and higher placental weights. ${ }^{11-15}$ In contrast to that, we encountered more number of small placentas which belonged to small to normally grown babies and was comparable with Edu et al. ${ }^{16}$

Risk of foetal loss is increased in diabetic pregnancy irrespective of glycemic control. ${ }^{17}$ Similarly, incidence of intrauterine death was higher in women in both the groups.

There was no significant increase in gross placental lesions among GDM on medication. ${ }^{18}$ The cord abnormalities such as hypercoiling, velamentous/marginal insertion and furcate cord were observed more in women with GDM on diet. ${ }^{19}$ Single umbilical artery is generally associated with gestational diabetes, but there were no such instances in our study.

\section{Placental histologic changes}

\section{Disturbances of villous maturation (DVM)}

DVM also known as distal villous immaturity were found in more than half of the cases in both groups. In contrast to the findings of Huynh et al, we did not find any differences between the two groups. ${ }^{20}$

Generally, in the last trimester of pregnancy, there is accelerated differentiation into terminal villi with increase in vasculosyncytial membrane formation. However, in pregnancies complicated by diabetes, this terminal differentiation is inhibited due to growth factor like activity of foetal insulin. Additionally, this is amplified by coexistent hypercoiling of the cord as seen in our study. ${ }^{21}$

As a result of defective villous maturation, there is reduced placental reserve leading to poor tolerance to acute hypoxia resulting in late intra uterine foetal loss. Since, this entity has a $10 \%$ risk of recurrence in subsequent pregnancies, it has been recommended to rescue the foetus by early delivery. ${ }^{22}$

\section{Derangements in uteroplacental circulation/Maternal vascular malperfusion (MVM)}

In our study, we observed greater incidence of features of MVM such as, infarcts, intervillous thrombus and increased syncytial knotting in both the groups. As described in literature, decidual vasculopathy was the prominent finding in women with coexistent preeclampsia/APLA as compared to isolated GDM. ${ }^{23}$ Retroplacental hematoma with blood dissecting into the intraparenchymal villous space and subsequent haemorrhagic necrosis was also noted in few cases of GDM on diet.

\section{Derangements in foetoplacental circulation/foetal vascular malperfusion (FVM)}

FVM frequently goes undetected antenatally and is commonly diagnosed with pathologic examination of placenta. Among the multitude of factors associated with FVM, maternal hyperglycemia plays a significant role. ${ }^{24}$

Pregnancy per se is a thrombogenic state. When it is combined with maternal hyperglycemia (prothrombotic tendency) and hypercoiling of the cord (thereby causing vascular stasis and ischemia), it results in thrombosis in the foetal vascular tree, leading to foetal growth restriction and increased perinatal mortality and morbidity. ${ }^{25,26}$

The following findings were seen as part of FVM in our study population: chorionic plate/ stem villous vessel thrombi, vascular ectasia, groups of avascular, fibrotic to hyalinized villi and villous stromal karyorrhexis.

\section{Villous capillary lesions}

A gamut of villous capillary lesions encompassing chorangiosis, chorangiomatosis and chorangiomas believed to be caused by preplacental hypoxia. ${ }^{27}$ 
GDM in pregnancy is commonly associated with chorangiosis, which is hypothesized to be caused by insulin/IGF-1 receptor mediated angiogenesis. ${ }^{25}$

In our series, we predominantly encountered chorangiosis and an occasional case of microscopic chorangioma, but none of the cases showed chorangiomatosis.

\section{Inflammatory lesions}

Acute chorioamnionitis was detected in a few cases of maternal hyperglycemia, of which more than half were complicated by preterm labour /preterm rupture of membranes. Severe maternal inflammatory response and early foetal inflammatory response were noted. ${ }^{28}$

Mild chronic villitis and chronic histiocytic intervillositis (CHIV) were also observed in some cases. Both the lesions have strong association with maternal autoimmune diseases.

Chronic histiocytic intervillositis is an uncommon placental lesion, characterized by a dense lymphohistiocytic infiltrate confined to the intervillous space. CHIV has a tendency for causing recurrent pregnancy loss due to the presence of persistent increase in memory $\mathrm{T}$ cells in subsequent pregnancies. ${ }^{29,30}$

Subchorionic pseudocysts, increased cell islands, foetal nucleated red blood cells and vascular ectasia are a known histologic sign of hypoxic lesions and found more in cases of GDM on diet. ${ }^{31}$

The strengths of our study include that all the women were booked at our hospital, the investigations, follow up and delivery was in the same institution and there was no loss to follow up and hence no attrition of data.

The limitations of our study include, smaller sample size and retrospective nature. Not all placentas with GDM were sent for pathological examination. Only those cases with maternal clinical conditions warranting special attention and those with adverse perinatal outcomes were sent for examination.

To summarize, Villous maturation defects, uteroplacental / fetoplacental malperfusion and villous capillary lesions are the essential placental changes which can result in adverse perinatal outcomes in women with hyperglycemia irrespective of the diabetic control.Further prospective studies with large sample size including all GDM placentas with exclusion of confounding factors would help in better characterization of placental lesions in different levels of glycemic control. Understanding the placental pathogenesis will help to develop protocols for prevention and treatment strategies to improve perinatal outcomes.

Funding: No funding sources

Conflict of interest: None declared
Ethical approval: The study was approved by the Institutional Ethics Committee

\section{REFERENCES}

1. World Health Organization - Diabetes country profiles, 2016. Available at: https://www.who.int/diabetes/countryprofiles/ind_en.pdf

2. Anjana RM, Deepa M, Pradeepa R, Mahanta J, Narain K, Das HK, et al. Prevalence of diabetes and prediabetes in 15 states of India: results from the ICMR-INDIAB population-based cross-sectional study. lancet Diabe Endocrinol. 2017;5(8):585-96.

3. Nguyen CL, Pham NM, Binns CW, Duong DV, Lee AH. Prevalence of gestational diabetes mellitus in eastern and southeastern Asia: a systematic review and meta-analysis. J Diabet Res. 2018;6536974:1-10.

4. Ramachandran A, Snehalatha C, Shyamala P, Vijay V, Viswanathan M. Prevalence of diabetes in pregnant women- a study from southern India. Diabet Res Clinic Pract. 1994;25(1):71-4.

5. Nallaperumal S, Bhavadharini B, Mahalakshmi MM, Maheswari K, Jalaja R, Moses A, et al. Comparison of the world health organization and the International association of diabetes and pregnancy study groups criteria in diagnosing gestational diabetes mellitus in South Indians. Ind $\mathbf{J}$ Endocrinol Metabol. 2013;17(5):906.

6. Government of India. Maternal and Health Division, Diagnosis and Management of Gestational Diabetes Mellitus: Technical and Operational Guidelines. New Delhi, India: Ministry of Health \& Family Welfare, New Concept Inform Syst; 2018.

7. Jarmuzek P, Wielgos M, Bomba-Opon D. Placental pathologic changes in gestational diabetes mellitus. Neuro Endocrinol Lett. 2015;36(2):101-5.

8. Gabbay-Benziv R, Baschat AA. Gestational diabetes as one of the great obstetrical syndromes-the maternal, placental, and fetal dialog. Best Pract Res Clinic Obstetr Gynaecol. 2015;29(2):150-5.

9. Seshiah V, Das AK, Balaji V, Joshi SR, Parikh MN, Gupta S. Gestational diabetes mellitus-guidelines. JAPI. 2006;54:622.

10. Benirschke K, Burton GJ, Baergen RN. Early development of the human placenta. In Pathology of the human placenta 2012:41-53. Springer, Berlin, Heidelberg.

11. Singer DB. The placenta in pregnancies complicated by diabetes mellitus. Perspect Pediatr Pathol. 1984 Fall;8(3):199-212.

12. Ramos A, Caimari F, Pujol IM, García-Patterson A, Ginovart G, Adelantado JM, Corcoy R. In women with gestational diabetes mellitus factors influencing growth have a larger effect on placental weight than on birth weight. Euro J Obstetr Gynecol Reproduc Biol. 2016;202:60-5.

13. Kucuk M, Doymaz F. Placental weight and placental weight-to-birth weight ratio are increased in diet-and exercise-treated gestational diabetes mellitus subjects 
but not in subjects with one abnormal value on $100-\mathrm{g}$ oral glucose tolerance test. J Diabet its Complicat. 2009;23(1):25-31.

14. Taricco E, Radaelli T, De Santis MN, Cetin I. Foetal and placental weights in relation to maternal characteristics in gestational diabetes. Placenta. 2003;24(4):343-7.

15. Baptiste-Roberts K, Salafia CM, Nicholson WK, Duggan A, Wang NY, Brancati FL. Maternal risk factors for abnormal placental growth: the national collaborative perinatal project. BMC pregnancy and childbirth. 2008;8(1):44.

16. Edu A, Teodorescu C, Dobjanschi CG, Socol ZZ, Teodorescu V, Matei A, Albu DF, Radulian G. Placenta changes in pregnancy with gestational diabetes. Rom J Morphol Embryol. 2016;57(2):50712.

17. Stillbirth Collaborative Research Network Writing Group. Association between stillbirth and risk factors known at pregnancy confirmation. JAMA: J Am Med Assoc. 2011;306(22).

18. Fox H. Pathology of the placenta in maternal diabetes mellitus. Obstetr Gynecol. 1969;34(6):7928.

19. Ezimokhai M, Rizk DE, Thomas L. Maternal risk factors for abnormal vascular coiling of the umbilical cord. Am J perinatol. 2000;17(08):441-6.

20. Huynh J, Yamada J, Beauharnais C, Wenger JB, Thadhani RI, Wexler D, Roberts DJ, Bentley-Lewis R. Type 1, type 2 and gestational diabetes mellitus differentially impact placental pathologic characteristics of uteroplacental malperfusion. Placenta. 2015;36(10):1161-6.

21. Redline RW. Distal villous immaturity. MiniSymposium: Placental and Trophoblastic pathology. Diagnost Histopathol. 2012;18(5):189-94.

22. Paciencia M, Dolley P, Jeanne-Pasquier C, Jacob B, Sadfi A, Leseigneur $P$, et al. Acute-placental dysfunction by villous-maturation defect and latefetal mortality. J Gynecol Obstet Biol Reprod. 2008;37(6):602-7.

23. Kovo M, Granot Y, Schreiber L, Divon M, BenHaroush A, Bar J. Pregnancy outcome and placental pathology differences in term gestational diabetes with and without hypertensive disorders. J MaternalFetal Neonat Med. 2016;29(9):1462-7.

24. Redline RW, Ravishankar S. Fetal vascular malperfusion, an update. Apmis. 2018;126(7):561-9.

25. Raymond W. Redline, Theonia K. Boyd, Drucilla J. Roberts. Diagnostic Pediatric Pathology: Placental and Gestational Pathol. Cambridge Uni Press; 2018:93-102.

26. Gorar S, Alioglu B, Ademoglu E, Uyar S, Bekdemir $\mathrm{H}$, Candan $\mathrm{Z}$, et al. Is there a tendency for thrombosis in gestational diabetes mellitus?. J Lab Physici. 2016;8(2):101.

27. Ogino S, Redline RW. Villous capillary lesions of the placenta: distinctions between chorangioma, chorangiomatosis, and Chorangiosis. Human Pathol. 2000;31(8):945-54.

28. Redline RW, Faye-Petersen O, Heller D, Qureshi F, Savell V, Vogler C. Amniotic infection syndrome: nosology and reproducibility of placental reaction patterns. Pediatr Development Pathol. 2003;6(5):435-48.

29. Boyd TK, Redline RW. Chronic histiocytic intervillositis: a placental lesion associated with recurrent reproductive loss. Human pathol. 2000;31(11):1389-96.

30. Ramya T, Chaitra V, Umamaheswari G. Chronic histiocytic intervillositis a rare placental cause of poor obstetric outcome: a clinicopathological study and literature review. Int $\mathbf{J}$ Reprod Contracept Obstet Gynecol. 2014 Dec;3(4):1146-1149.

31. Stanek J, Weng E. Microscopic chorionic pseudocysts in placental membranes: a histologic lesion of in utero hypoxia. Pediatr Development Pathol. 2007;10(3):192-8.

Cite this article as: Natarajan L, Maheswari GU. Gestational hyperglycemia on diet and medication: impact on placental pathology and pregnancy outcomes. Int J Reprod Contracept Obstet Gynecol 2019;8:3350-6. 